\title{
Performance of force standard machines with compensation of lever arm distortion
}

\author{
Ulrich Kolwinski, Daniel Schwind \\ GTM Gassmann Testing and Metrology, Philipp Reis Strasse 6, 64404 Bickenbach, Germany
}

\begin{abstract}
The demand for lower uncertainties in force measurement is increasing. Deadweight force standard machines are known to yield the lowest measurement uncertainty in force realization. However, their capacities cannot be extended indefinitely as they become too large in size and prohibitively expensive. Lever amplification of a deadweight force is an option for higher capacities in force realization. This paper describes the performance of a force standard machine with a new method (patent pending) for automatic compensation of lever arm distortion in order to keep the amplification ratio constant.
\end{abstract}

\section{Section: RESEARCH PAPER}

Keywords: Force; Lever Arm; Calibration

Citation: Ulrich Kolwinski, Daniel Schwind, Performance of force standard machines with compensation of lever arm distortion, Acta IMEKO, vol. 3, no. 2, article 6, June 2014, identifier: IMEKO-ACTA-03 (2014)-02-06

Editor: Paolo Carbone, University of Perugia

Received February $13^{\text {th }}, 2013$; In final form December $16^{\text {th }}, 2013$; Published June 2014

Copyright: (C) 2014 IMEKO. This is an open-access article distributed under the terms of the Creative Commons Attribution 3.0 License, which permits unrestricted use, distribution, and reproduction in any medium, provided the original author and source are credited

Funding: This work was supported by Measurement Science Consultancy, The Netherlands

Corresponding author: Daniel Schwind, email: Daniel.schwind@gtm-gmbh.com

\section{INTRODUCTION}

GTM's force standard machines (FSM) for higher loads use a lever system to amplify forces with high accuracy, by having strain controlled support of the lever. On each force introduction point of the lever, the bending moments are measured by means of strain gauges which are bonded to elastic hinges. Force introduction points are the connection point of the masses (mass hinge), the support of the lever at its fulcrum (support hinge) and the connection point on the loaded side of the lever (load hinge).

The sum of the bending moments of the hinges is the feedback value for a closed loop control system of the drive of the lever-side crosshead, which is always in active mode while amplifying the force, with a setpoint of zero.

\section{DESCRIPTION}

A FSM with lever amplification has been designed and developed by GTM Gassmann Testing and Metrology, Germany, and has been installed at the National Physical Laboratory, India in 2010. The machine consists of a deadweight part with $100 \mathrm{kN}$ capacity, a lever part with $1 \mathrm{MN}$ capacity, and a lever with a ratio of 1:10 supported by strain controlled hinges, see Figure 1. The main construction principles of the $100 \mathrm{kN} / 1 \mathrm{MN}$ FSM of lever type with strain

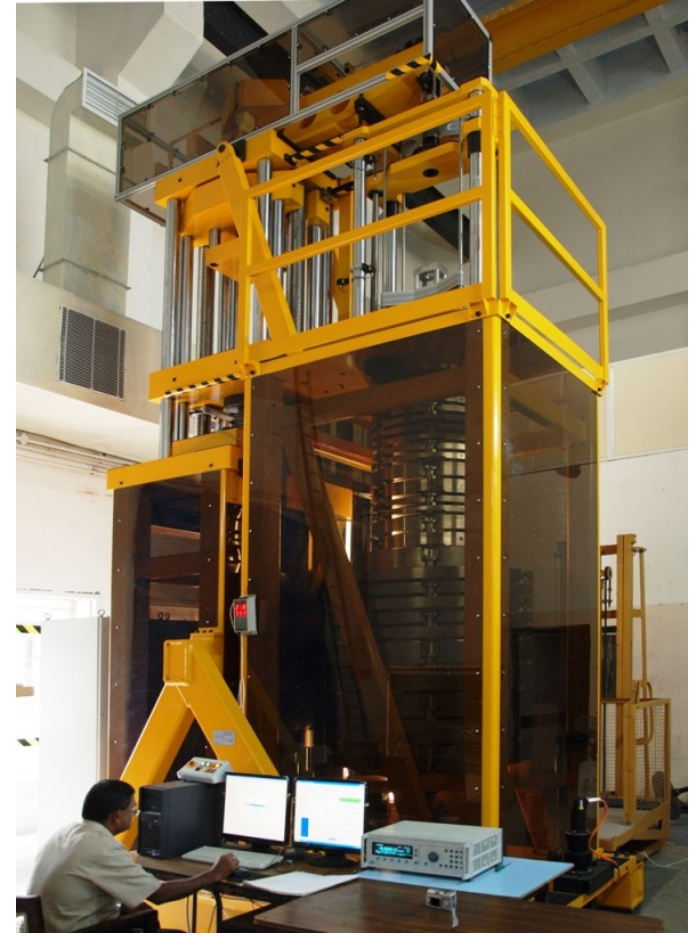

Figure 1. 100 kN / 1 MN FSM of NPL India. 
Table 1. Measuring ranges of the FSM.

\begin{tabular}{|l|c|c|}
\hline Machine Part & Deadweight & Lever \\
\hline Measuring Ranges & $1-10 \mathrm{kN}$ & $10-100 \mathrm{kN}$ \\
& $2-20 \mathrm{kN}$ & $20-200 \mathrm{kN}$ \\
& $5-50 \mathrm{kN}$ & $50-500 \mathrm{kN}$ \\
& $10-100 \mathrm{kN}$ & $100-1000 \mathrm{kN}$ \\
\hline
\end{tabular}

controlled hinges were previously described in [1]. In order to reduce the expanded uncertainty of the lever amplification forces to the range of $10^{-5}$, the machine design was completely re-developed. Many optimized or newly designed features have been incorporated in the machine. These include:

1) A machine frame with different supporting beams for the deadweight side and the lever side respectively, for higher stiffness.

2) Further developed mass disks to avoid asymmetric distortions, to reduce the risk of mass contacts, to improve the smooth asymptotic load change and to reduce side-ways motion.

3) A lever designed for higher stiffness and higher stability of the lever ratio, which is covered by an enclosure to reduce ambient influences (Figure 2).

4) The mass stack comprising 26 mass disks of various denominations, adjusted to the local ' $\mathrm{g}$ ' value and air density with a relative uncertainty of $5 \cdot 10^{-6}(k=2)$, so that all the forces in the ranges given in Table 1 can be applied sequentially.

5) A four column hanger made of an aluminium and steel combination to realize a low lying balance point and to allow a temperature chamber installation.

6) A load-depending compensation of the lever arm distortion was realized with special strain controlled hinges.

\section{LEVER ARM DISTORTION}

It is known that a lever arm will deform when loads are applied to its ends. This distortion reduces the effective lever length especially on the long side of the lever, see Figure 3. The distortion of the lever arm directly influences the lever amplification ratio. As the generated force at the lever side of the machine is a result of the deadweight force multiplied by the amplification ratio, a systematic error in measurement

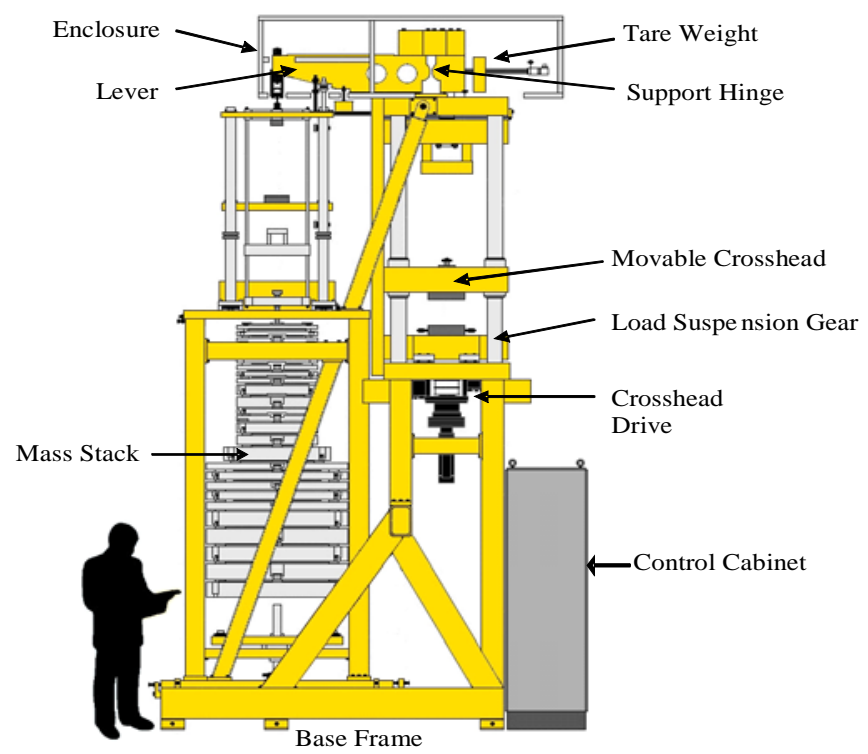

Figure 2. Schematic view of the $1 \mathrm{MN} \mathrm{FSM}$ at NPL(I).

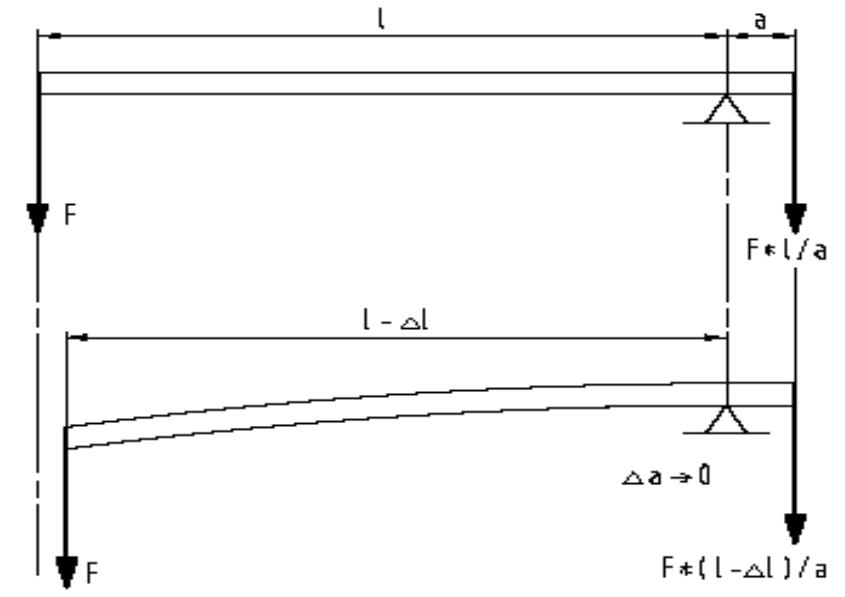

Figure 3. Lever arm reduction by distortion.

results from any distortion of the lever arm which is not taken into consideration. In order to reduce this systematic error it is known from practise that some degree of mechanical compensation can be applied. However, great effort, usually by trial and error, is necessary for this.

To improve this situation GTM has designed an automatic system to compensate the lever arm distortion, using strain controlled hinges (Figure 4). The lever bearings with elastic hinges are completely free of friction and wear and define the pivot and load introduction points of the lever with the best possible precision, including long term. The ratio can be set exactly through the adjustment of the long lever arm length.

The strain controlled hinges are equipped with measuring circuits for bending moments and additional measuring circuits for axial loads. The measurement of axial loads can be achieved relatively easily since it is not necessary to measure the axial force with extreme precision as only a fraction of the axial measurement signal is necessary for the compensation.

The different strain controlled hinges must however have their sensitivity exactly adjusted. With the help of these strain controlled hinges in this type of machine the systematic effect of the lever ratio reduction caused by distortion can be compensated.

The load-dependent distortion of the lever arm is compensated by the evaluation and sensitivity adjustment of the measured bending moments and axial forces. A fraction of the

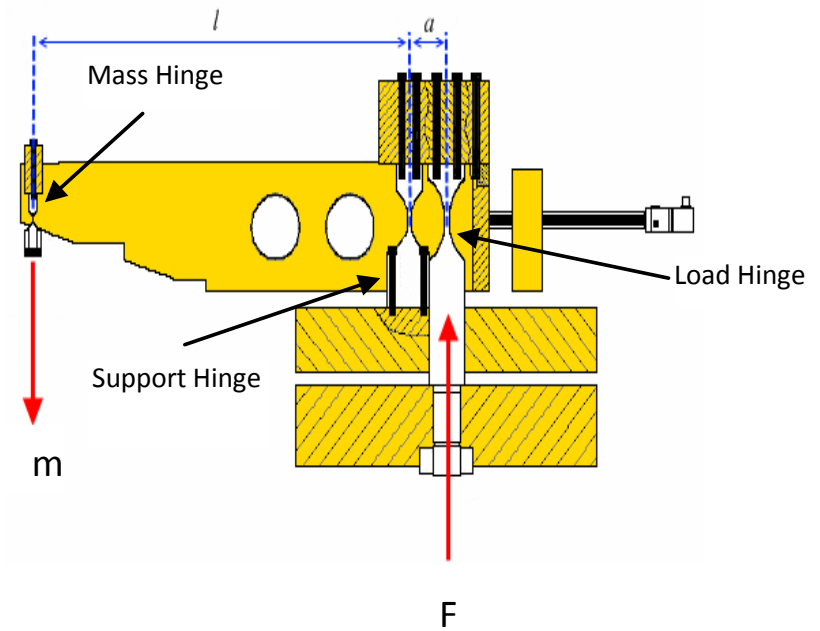

Figure 4. GTM Lever amplification System. 
measured axial force signal is added to the sum signal of the bending moments. This is the corrected feedback value for the closed loop control system of the drive of the lever-side crosshead. As the corrected feedback value is generated in real time and automatically during operation of the machine no additional time and effort for calibration tasks is necessary.

\section{DESCRIPTION OF COMPENSATION}

Equations (1) and (2) describe the balanced system. In the balanced system the sum of all moments is zero

$\sum M=0=m \cdot g \cdot\left(1-\frac{\rho_{a}}{\rho_{m}}\right) \cdot l+F \cdot a+M_{b}-\Delta F \cdot a$.

The force on the lever side is:

$$
-F=m \cdot g \cdot\left(1-\frac{\rho_{a}}{\rho_{m}}\right) \cdot \frac{l}{a}+\frac{M_{b}}{a}-\Delta F
$$

with

$$
\begin{array}{ll}
F: & \text { force on the lever side }[\mathrm{N}] \\
m: & \text { mass on the deadweight side }[\mathrm{kg}] \\
g: & \text { local acceleration of gravity }\left[\mathrm{m} / \mathrm{s}^{2}\right] \\
\rho_{\mathrm{a}}: & \text { density of air }\left[\mathrm{kg} / \mathrm{m}^{3}\right] \\
\rho_{\mathrm{m}}: & \text { density of mass }\left[\mathrm{kg} / \mathrm{m}^{3}\right] \\
l: & \text { long lever arm }[\mathrm{m}] \\
a: & \text { short lever arm }[\mathrm{m}] \\
M_{b}: & \text { sum of bending moments of lever support }[\mathrm{N} \cdot \mathrm{m}] \\
\Delta \mathrm{F}: & \text { systematic force error of } F \text { due to distortion }[\mathrm{N}]
\end{array}
$$

A previously developed method was that the closed loop control system of the drive of the lever-side crosshead moves the crosshead in such a way that the sum signal of all bending signals of the elastic hinges is zero. The systematic force error out of the lever arm distortion had to be minimized by other mechanical means.

For the new electronic method for the compensation of lever arm distortion a correction force $F_{\text {corr }}$ is determined from the axial load signal and added to the sum of the bending signals. This is done in such a way that a modified sum of the bending moments $M_{b}^{\prime}$ includes the correction moment $M_{\text {corr }}$ which is generated by $F_{\text {corr }}$

$M_{\text {corr }}=F_{\text {corr }} \cdot a$.

The modified sum of the bending moments $M_{b}^{\prime}$ is

$M_{b}^{\prime}=M_{b}+M_{\text {corr }}=M_{b}+F_{\text {corr }} \cdot a$.

The correction force $F_{\text {corr }}$ has to be determined in such a way that it is nearly equal to the systematic force error $\Delta F$. In that case the modified sum of the bending moments $M_{b}^{\prime}$ compensates the systematic force error $\Delta F$.

$$
-F=m \cdot g \cdot\left(1-\frac{\rho_{a}}{\rho_{m}}\right) \cdot \frac{l}{a}+\frac{M_{b}^{\prime}}{a}-\Delta F .
$$

From a practical point of view a small deliberate deflection of the hinges is used to achieve the compensation. The force which is needed for the deflection of the hinges is equal to the systematic force error. This compensation method can only be used with strain controlled hinges and not with knife edge bearing designs.

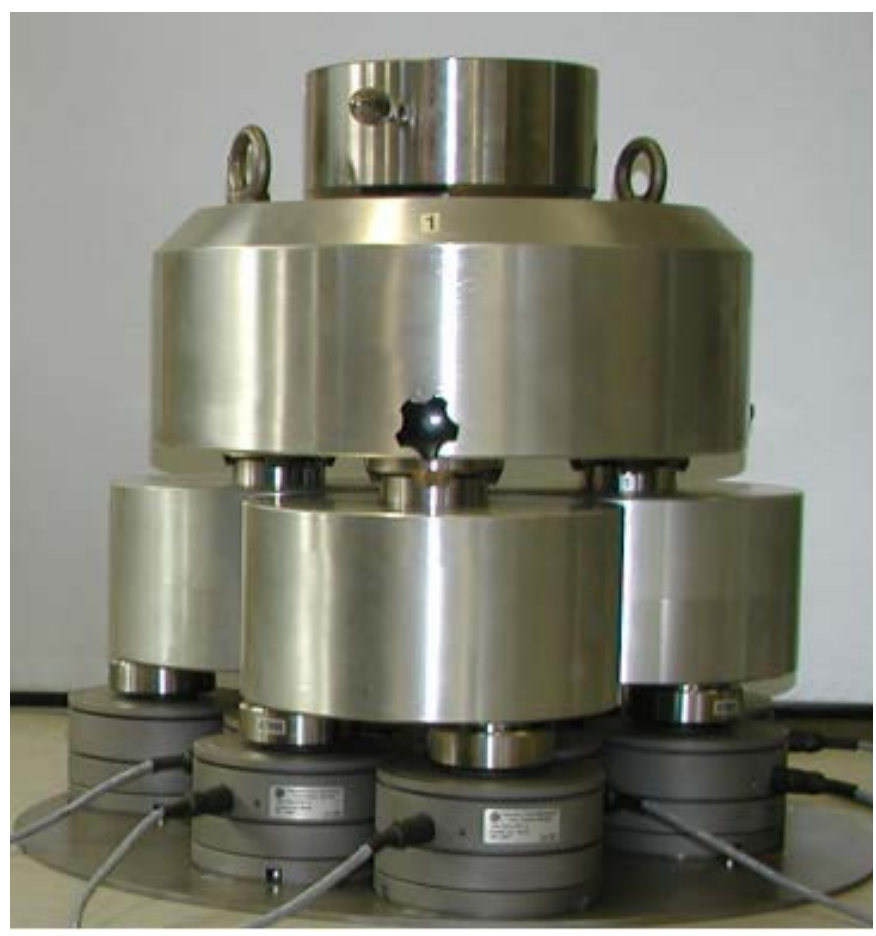

Figure 5. Build-Up-System 900kN.

The necessary correction force $F_{\text {corr }}$ can be described by a polynomial function and can be calculated from the measured axial force of the elastic hinge. The measurement error of the axial force has a negligible effect on the measurement uncertainty of the FSM. For example: if a correction of $3.5 \cdot 10^{-4}$ is necessary and the measurement error of the axial force is $0.5 \%$ the effect on the measurement uncertainty of the FSM is $1.75 \cdot 10^{-6}$.

\section{SELF-CALIBRATION OF LEVER FORCES}

In order to determine the dependency between load and correction force $F_{\text {corr }}$ a self-calibration procedure of the FSM can be carried out. This procedure may be important for an independent traceability of the forces in national metrology institutes. For this purpose several force transfer standards of similar type can be calibrated with smallest measurement uncertainty in the deadweight part of the FSM. Afterwards these calibrated force transfer standards are combined to buildup systems and measurements can be done in the lever amplification part of the FSM. The measurements can be performed with a single transducer and by use of build-upsystems with up to nine transducers (Figure 5).

Examples of the measuring ranges of build-up-systems according to this procedure are as follows:

$10-100 \mathrm{kN}$ (with a single transfer standard)

$30-300 \mathrm{kN}$ (with a system of three transfer standards)

$100-900 \mathrm{kN}$ (with a system of nine transfer standards)

\section{LINEARITY OF LEVER FORCES}

An example for the linearity error of lever forces of a $1000 \mathrm{kN}$ FSM with and without the described lever arm compensation is shown in Figure 6. In this case the linearity errors are not identified with the self-calibration method, but by comparison with the calibration results of several force transfer standards calibrated at PTB. 


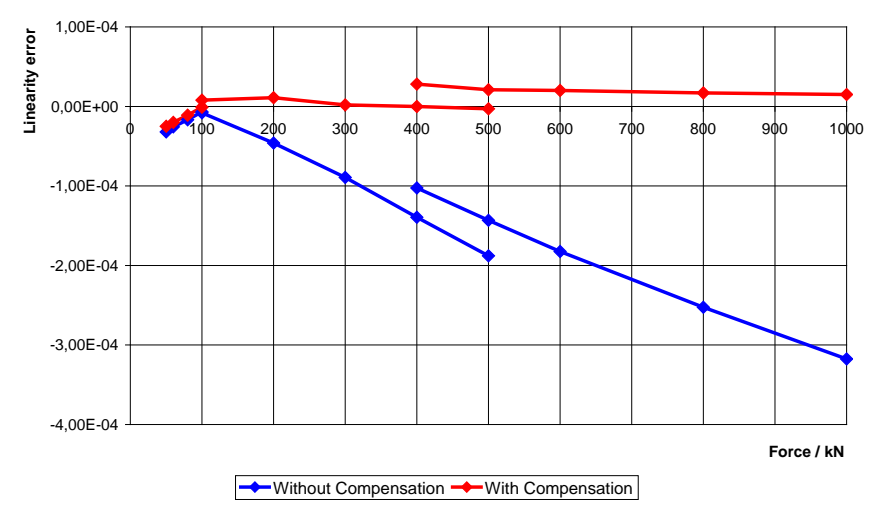

Figure 6. Linearity error of Lever Force.

Without any lever arm compensation the relative linearity error (means the relative deviation to PTB) increases up to more than $3 \cdot 10^{-4}$ at $1000 \mathrm{kN}$. In case the electronic lever arm distortion compensation is used the linearity error is nearly constant and less than $5 \cdot 10^{-5}$ across the whole measuring range. The electronic compensation of lever arm distortion reduces the linearity error significantly.

\section{UNCERTAINTY OF LEVER FORCES}

The achieved uncertainties for the lever amplification forces of the NPL(I) FSM were calculated according the EURAMET/cg-04 calibration guide [3]. Chapter 4.3 in the guide describes the uncertainties to be considered. The detailed uncertainty contributions for the FSM of NPL(I) have been previously discussed in detail in [2].

The following Table 2 presents the achieved uncertainty contributions for the smallest force on lever side and the calculated expanded relative uncertainty, where

\footnotetext{
m: $\quad$ mass on deadweight side

g: $\quad$ local acceleration of gravity

$\rho_{\mathrm{a}}: \quad$ density of air

$\rho_{\mathrm{m}}: \quad$ density of mass

$\Delta \mathrm{F}_{\mathrm{DW}}$ : uncertainty contribution due to measurements on deadweight side
}

Table 2. Uncertainty of $10 \mathrm{kN}$ on lever side.

\begin{tabular}{|c|c|c|c|c|c|c|c|}
\hline quantity & estimate & $\begin{array}{l}\text { relative half } \\
\text { width }\end{array}$ & distribution & divisor & $\begin{array}{c}\text { relative } \\
\text { standard } \\
\text { uncertainty }\end{array}$ & $\begin{array}{l}\text { sensitivity } \\
\text { coefficient }\end{array}$ & $\begin{array}{c}\text { relative } \\
\text { uncertainty } \\
\text { contribution }\end{array}$ \\
\hline $\mathrm{m}$ & $102,14678 \mathrm{~kg}$ & & Gaussian & & $2,51 \mathrm{E}-06$ & 1 & $\begin{array}{l}2,51 \mathrm{E}-06 \\
\end{array}$ \\
\hline $\mathrm{g}$ & $9,791245 \mathrm{~m} / \mathrm{s}^{2}$ & $5,00 \mathrm{E}-07$ & rectangular & $\sqrt{3}$ & $2,89 \mathrm{E}-07$ & 1 & $2,89 \mathrm{E}-07$ \\
\hline$\rho_{a}$ & $1,15 \mathrm{~kg} / \mathrm{m}^{3}$ & $1,50 \mathrm{E}-03$ & rectangular & $\sqrt{3}$ & $8,66 \mathrm{E}-04$ & $1,84 \mathrm{E}-04$ & $1,59 \mathrm{E}-07$ \\
\hline$\rho_{m}$ & $6255 \mathrm{~kg} / \mathrm{m}^{3}$ & & Gaussian & & $1,12 \mathrm{E}-02$ & $1,84 \mathrm{E}-04$ & $2,06 \mathrm{E}-06$ \\
\hline$\Delta \mathrm{F}_{\mathrm{OW}}$ & $100 \mathrm{kN}$ & & Gaussian & & $1,10 \mathrm{E}-05$ & 1 & $1,10 \mathrm{E}-05$ \\
\hline$\Delta F_{L}$ & $100 \mathrm{kN}$ & & Gaussian & & $1,20 \mathrm{E}-05$ & 1 & $1,20 \mathrm{E}-05$ \\
\hline$\Delta \mathrm{F}_{\text {Dis }}$ & $0 \mathrm{kN}$ & $5,00 E-05$ & rectangular & $\sqrt{3}$ & $2,89 \mathrm{E}-05$ & 1 & $2,89 \mathrm{E}-05$ \\
\hline$\Delta \mathrm{F}_{\text {msst }}$ & $0 \mathrm{kN}$ & $1,00 \mathrm{E}-05$ & triangle & $\sqrt{6}$ & $4,08 \mathrm{E}-06$ & 1 & $4,08 \mathrm{E}-06$ \\
\hline$\Delta \mathrm{F}_{\mathrm{E} c c}$ & $0 \mathrm{kN}$ & $1,00 \mathrm{E}-05$ & triangle & $\sqrt{6}$ & $4,08 \mathrm{E}-06$ & 1 & $4,08 \mathrm{E}-06$ \\
\hline$\Delta \mathrm{F}_{\text {Sens }}$ & $0 \mathrm{kN}$ & $1,50 \mathrm{E}-05$ & rectangular & $\sqrt{3}$ & $8,66 \mathrm{E}-06$ & 1 & $8,66 \mathrm{E}-06$ \\
\hline & & & & \multicolumn{3}{|c|}{\begin{tabular}{|l|} 
Rel. Uncertainty: \\
Expanded relative Uncertainty $(k=2):$
\end{tabular}} & $\begin{array}{ll}3,5 \mathrm{E}-05 \\
0,0070 \%\end{array}$ \\
\hline
\end{tabular}

$\Delta \mathrm{F}_{\mathrm{L}}: \quad$ uncertainty contribution due to measurements on lever side

$\Delta \mathrm{F}_{\mathrm{Dis}}$ : uncertainty contribution due to the distortion of the lever system

$\Delta \mathrm{F}_{\text {inst }}$ : uncertainty contribution due to the instability of the control system

$\Delta \mathrm{F}_{\mathrm{Ecc}}$ : uncertainty contribution due to an eccentric load introduction

$\Delta \mathrm{F}_{\text {sens }}$ : uncertainty contribution due to the response sensitivity of the lever system

\section{CONCLUSIONS}

Load-dependent compensation of a lever arm distortion can be achieved with special strain controlled hinges. This compensation reduces the measurement uncertainty of lever force standard machines. Machines with this type of compensation of lever arm distortion can achieve relative expanded uncertainties of less than $9 \cdot 10^{-5}$ on lever side.

\section{REFERENCES}

[1] G. Navrozidis, F. Strehle, D. Schwind, H. Gassmann, “Operation of a New Force Standard Machine at Hellenic Institute of Metrology", IMEKO 2001, Istanbul.

[2] S.K. Jain et al., "Metrological characterization of the new $1 \mathrm{MN}$ force standard machine of NPL India", Measurement 45 (2012) pp.590-596

[3] Uncertainty of Force Measurements, Calibration Guide, EURAMET/cg-04/v.01, March 2010. 